\title{
STUDY OF THE INFLUENCE OF THE DIAMETER OF MODIFIED TOOLS WITH INTERNAL COOLING CHANNELS UNDER DIFFERENT THERMAL FLOWS
}

\author{
P. H. P. França, ABSTRACT \\ and L. R. R. da Silva \\ Federal University of Uberlandia, School of \\ In this work, the effect on heat generation at the chip-machine tool \\ interface was studied by varying the diameter of internal grooves of a \\ tool for the turning process. This tool is modified with internal \\ channels that circulate water as a coolant through a closed system. As \\ an output parameter, the maximum cutting temperature at the chip- \\ tool interface was studied. The input parameters were the thermal flux \\ present at the chip-tool interface and the diameter of the internal \\ channels present in the cutting tool. All the analysis of variation of \\ the internal channels of the tools and also of the thermal flow exerted \\ on the chip-tool interface were carried out using the finite element \\ method by the Ansys ${ }^{\circledR}$ Workbench 19.2 software. The main one was \\ that the variation in the diameter of the tool's internal grooves does \\ not expressly impact the machining specifications. \\ Received: Jul 23, 2021 \\ Revised: Aug 10, 2021 \\ Accepted: Aug 15, 2021 \\ Keywords: heat transfer enhancement, optimal geometry, eccentricities
}

\section{INTRODUCTION}

According to Machado et al. (2011) any effort to increase productivity and reduce cost must be taken into account in manufacturing systems. Thus, the search for increased tool life or production speed is important for modern industry.

According to Santos and Sales (2007), almost all mechanical energy involved in the machining process is transformed into thermal energy, with only 1 to $3 \%$ being converted into elastic energy. The temperature in the tool has always been a factor with a high impact on its tool life.

Studies carried out such as the one by Santos et al. (2017), for example, in which they turned the 7075T6 aluminum alloy, show that the increase in cutting speed is the most responsible for the increase in temperature obtained through the tool-part thermocouple technique, despite other factors with the cutting advance also influence the results, according to.

According to Silva et al. (2018), when milling vermicular cast iron, it is also possible to state that the temperature increases proportionally with the cutting speed, due to the greater kinetic energy involved. The author measured the chip temperature using a thermographic camera.

Among the most used methods for reducing tool temperature is dry machining, which there is no forced method for removing heat from the tool; spurt, where the cutting fluid soaks the cutting zone; minimum amount of lubricating fluid (MQL), in which the cutting fluid is atomized into compressed air. In addition to the traditional methods, there are other methods used such as the use of heat pipes to remove heat from the tool Chiou et al. (2002), internally cooled tool or tool holder systems.

The work by Jeffries and Zerkle (1970), considered the first study carried out in which they numerically modeled a fluid that changed phase when exchanging heat with the tool. Rozzi et al. (2011) adapted a cutting tool with micro flutes in order to circulate liquid nitrogen in an open circuit, and remove heat from the fluid in the turning of AISI 416 stainless steel, resulting in an increase in tool life compared to dry machining. The work by Ferri et al. (2014) consisted of the external cylindrical turning of the AA6082-T6 aluminum alloy, and aimed to compare conventional carbide tools with carbide tools with the presence of internal channels in which water circulated in a closed circuit. The author found that the tool with internal coolant had a lower temperature, with greater emphasis on the cutting condition that has the greatest depth of cut.

This work aims to study the influence of the diameter of internal tool channels of a new cooling system in machining. This system is based on the modification of the tool and tool holder set through the insertion of internal coolant channels in the geometry of this set. The purpose of these channels is to reduce the high temperatures generated during machining, formed due to the high friction between the part and the tool and also by the mechanical energy transformed into heat during the material's shear. 


\section{ICT - INTERNAL COOLED TOOLS}

The planning system is composed of two subsystems, the cooling subsystem and the machining subsystem. The refrigeration sub-system is composed of an adapted vertical freezer, which the refrigerant, r401a, cools a secondary fluid, in this case water, until close to the solidification temperature. This water is stored in a reservoir, which is immersed in the evaporator, serving as a secondary heat exchanger.

The secondary fluid is pumped to the machining sub-system, which is mainly composed of the tool and the tool holder, through fluids connected to the primary fluid through flexible tubes. Both the cutting tool and the tool holder have galleries inside, machined through electro-erosion by a rotating electrode in order to allow thermal exchange and reduce the temperature of the insert.

\section{METHODOLOGY}

Figure 1 shows the layout of the simulated set of three components (tool, tool holder and clamp).

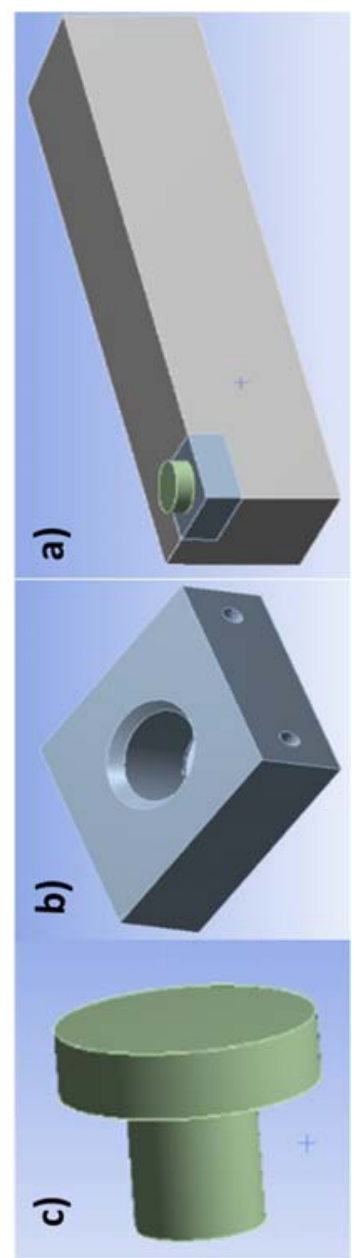

Figure 1. Schematic of the set used in the simulations.
For all tests, the same geometry was used for the tool holder and modified tool, however, as a design variable, it was decided to vary the diameter of the internal coolant channels of the tool. Figure 2 illustrates the geometry of the internal channels made in the tool and figure 3 depicts the geometry of the tool holder channels.

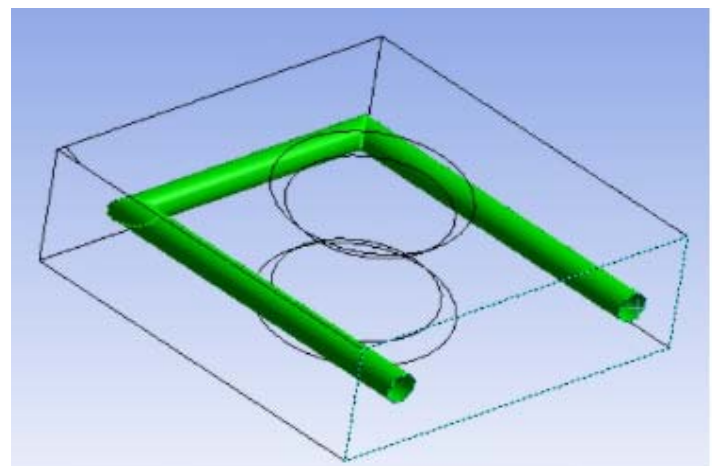

Figure 2. Geometry of the tool's internal channels.

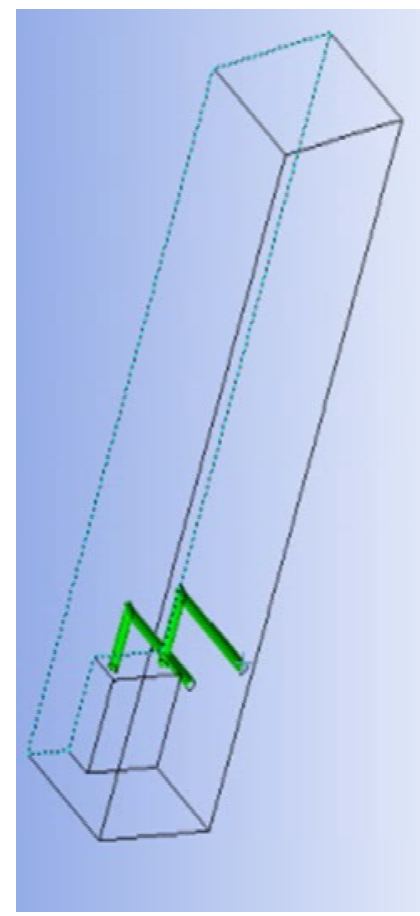

Figure 3. Geometry of the internal tool holder channels.

To study the influence of thermal convection generated on machining temperatures, in addition to the variation in channel diameters, the parameters indicated in table 1 were used, which were based on values obtained in the literature by (Santos \& Sales, 2007) and Carvalho (2005). 
Table 1- Diameter of internal channels.

Diameter Channels

(mm)

$$
1,5
$$

3,0

Due to the complexity of parameters involved and uncontrollable variables of the system, it was decided to make some assumptions, described in table 2 .

Table 2 - Assumptions made in the simulations.

Ambient convection coefficient $20 \mathrm{~W} / \mathrm{m}^{2}{ }^{\circ} \mathrm{C}$

Tool holder and clamp emissivity of 0.9

Tool emissivity of 0.7

Coolant thermal flow $2000 \mathrm{~W} / \mathrm{m}^{2}{ }^{\circ} \mathrm{C}$ with a temperature of $-20^{\circ} \mathrm{C}$.

Homogeneous tool material (carbide).

Homogeneous Clamp and Toolholder material (structural steel)

During the tests, it was considered that the tool holder body and clamp are made of 1020 structural steel and the tool body is made of carbide. However, due to the non-existence of carbide in the Ansys ${ }^{\circledR}$ library, it was decided to make changes to the tungsten carbide material, taking into account some properties due to the addition of other alloying elements, resulting in the properties described as shown in table 3.

Table 3 - Main properties adopted for carbide.

\begin{tabular}{ll}
\hline Poisson's Coefficient & 0,22 \\
Thermal Expansion & 5,6 \\
$\begin{array}{l}\text { Coefficient } \\
\left(10^{-6} / \mathrm{K}\right)\end{array}$ & \\
$\begin{array}{l}\text { Thermal Conductivity } \\
(\mathrm{W} / \mathrm{mK}) \quad 71\end{array}$ & \\
$\begin{array}{l}\text { Density }\left(\mathrm{kg} / \mathrm{m}^{3}\right) \\
\text { Young's Module }(\mathrm{Gpa})\end{array}$ & 540 \\
$\begin{array}{l}\text { Compression Resistance } \\
(\mathrm{GPa})\end{array}$ & 4,3 \\
Tensile strength $(\mathrm{GPa})$ & 1,6 \\
\hline
\end{tabular}

All carbide property values used were based on the G5 tool model taken from the Everloy® product catalog.

\section{RESULTS AND DISCUSSION}

To avoid errors due to the formation of the system mesh, before carrying out the tests, a mesh refinement was carried out focused on the cutting edge of the tool, which is the location of interest and where the machining temperatures are formed. The refinement tests were carried out using a tool with a diameter of $3 \mathrm{~mm}$ internal channels, with a thermal flux of $40 \mathrm{~W}$ at the chip-tool interface, without internal fluid circulation. Figure 4 shows the results obtained for the refinement as a function of time.

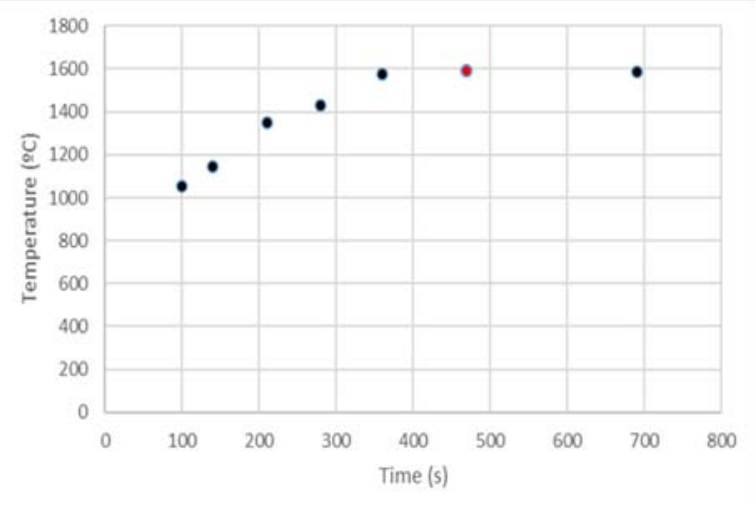

Figure 4. Refinement of the system mesh, considering the temperature and time for each test.

Note that from the condition with a time of 470 seconds, the results showed equal temperatures of $1582.8{ }^{\circ} \mathrm{C}$, indicating a permanent mesh regime. Therefore, it was decided to use the refinement of the mesh generated under this condition to save time and computational resources. Figure 5 shows the mesh used.

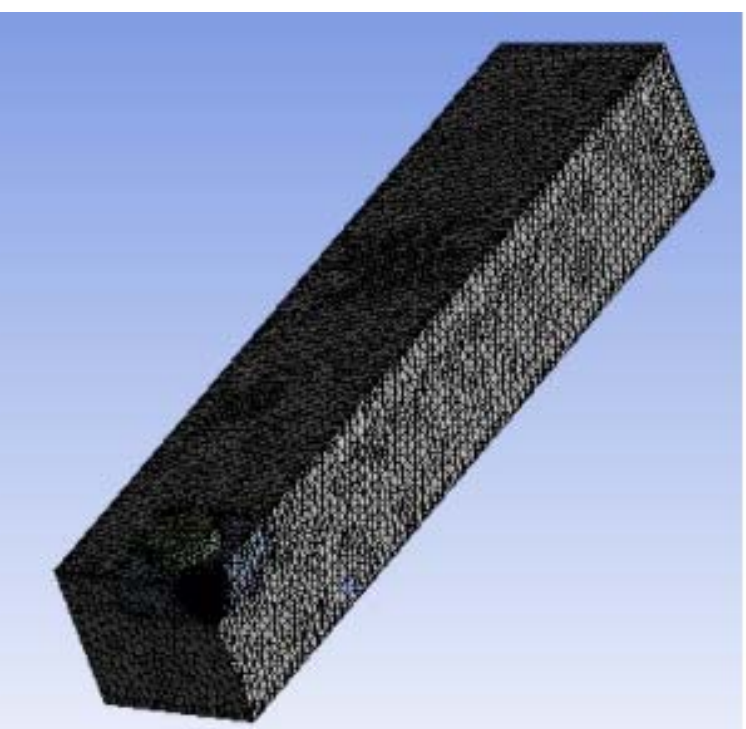

Figure 5. Mesh used to carry out the simulations.

The graph in figure 6 demonstrates the results of the maximum temperature of the cutting interface under different thermal fluxes.

When varying the diameter of the channels, a significant difference in the machining temperatures was not noticed for the same thermal flow condition. A hypothesis for this result is due to the thermal exchange limit that the coolant reaches when circulating in the tool. Thus, even with the increase in the diameter of the channels, the heat flux received by the secondary coolant that circulates in the tool does not remove heat at the chip-tool interface, only in the regions. 


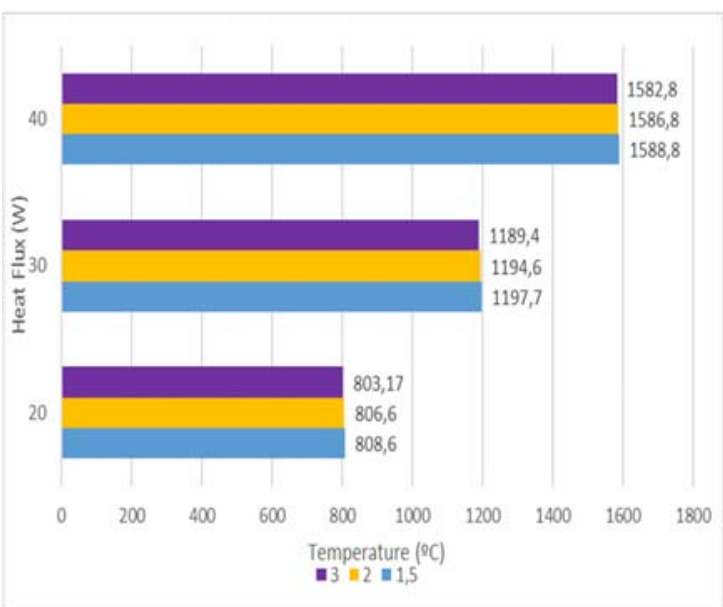

Figure 6. Maximum temperatures in the cutting zone under different thermal flows and diameters of the cooling channels.

However, when comparing the influence of the thermal flux exerted on the tool, a large variation in temperatures is observed. This large temperature increase can be explained by the small area where heat is generated, between the part and the tool, causing the heat to remain concentrated at this point.

\section{CONCLUSIONS}

From the analyzes carried out varying the diameter of the tool's internal channels, and the thermal flow, it was possible to conclude that:

- Varying the diameter of the tool grooves did not significantly affect the machining temperatures.

- With the increase of the thermal flow at the chip-tool interface, higher temperatures were obtained.

- The highest temperature reached was in the most critical condition, with a tool with a $1.5 \mathrm{~mm}$ internal channel diameter and $40 \mathrm{~W}$ thermal flow, with a temperature value of $1588,8 \mathrm{~W}$.

- After the simulations reached the permanent loop regime, it was possible to obtain stable temperature values.

\section{ACKNOWLEDGEMENTS}

The authors would like to thank the sustainable manufacturing group (GMS) at the Federal University of Uberlândia (UFU).

\section{REFERENCES}

Carvalho, S. R., 2005, Determinação do campo de temperatura em ferramentas de corte durante um processo de usinagem por torneamento. $123 \mathrm{f}$. Tese de Doutorado - Universidade Federal de Uberlândia,
Uberlândia.

Chiou, R. Y., Chen, J. S. J., Lu, L., \& Cole, I.., 2002, Prediction of heat transfer behavior of carbide inserts with embedded heat pipes for dry machining. ASME International Mechanical Engineering Congress and Exposition, Proceedings, 83-90. https://doi.org/10.1115/IMECE2002-32656

Da Silva, L. R. R., Filho, A. F., Costa, E. S., Marcucci Pico, D. F., Sales, W. F., Guesser, W. L., \& Machado, A. R., 2018, Cutting Temperatures in End Milling of Compacted Graphite Irons. Procedia Manufacturing, 26, 474-484. https://doi.org/10.1016/j.promfg.2018.07.056

Jeffries, N. P., \& Zerkle, R. D., 1970, Thermal analysis of an internally-cooled metal-cutting tool. International Journal of Machine Tool Design and Research, 10(3), 381-399. https://doi.org/10.1016/0020-7357(70)90019-3

Machado, A. R., Abrão, A. M., Coelho, R. T., \& Da Silva, M. B., 2015, Teoria da Usinagem dos Materiais. Edgard Blucher, São Paulo.

Rozzi, J. C., Sanders, J. K., \& Chen, W., 2011, The Experimental and Theoretical Evaluation of an Indirect Cooling System for Machining. 133(March 2011), 1-10. https://doi.org/10.1115/1.4002446

Santos, M. C., Araújo Filho, J. S., Barrozo, M. A. S., Jackson, M. J., \& Machado, A. R., 2017, Development and application of a temperature measurement device using the tool-workpiece thermocouple method in turning at high cutting speeds. International Journal of Advanced Manufacturing Technology, 89(5-8), 2287-2298. https://doi.org/10.1007/s00170-016-9281-1

Santos, S. C., \& Sales, W. F., 2007, Aspectos tribológicos da usinagem dos materiais. Artliber, 53(9), 1689-1699. https://doi.org/10.1017/CBO9781107415324.004 